\title{
Partial deoxygenation of biomass derived pyrolysis liquids
}

\author{
Murlidhar Gupta*, Jacques Monnier, Eric Turriff, Mark Boyd \\ Natural Resources Canada, CanmetENERGY, 1 Haanel Drive, Ottawa, Ontario K1A 1M1, Canada
}

\begin{abstract}
Biomass pyrolysis liquids (also known as bio-oil), are derived from renewable lignocellulosic biomass residues by fast pyrolysis process. These second-generation oxygenated hydrocarbon resources have the potential to partially substitute for petroleum-derived feedstocks and thus enhance the economic and environmental sustainability of our natural resources. However, in contrast to petroleum fuels, biomass-derived pyrolysis liquids contain a large amount of oxygen, usually $40-50 \% \mathrm{wt} \%$ (wet basis). This undesirable high oxygen content in pyrolysis liquids is considered as the primary reason for its high polarity, high acidity, lower stability, lower energy density and very low miscibility with conventional crude refining feedstocks. There are two major pathways for upgrading the pyrolysis liquids. While hydrodeoxygenation route is one of the most explored options, it requires production and supply of large amounts of expensive hydrogen at high pressures, mandating large and centralized upgrading plants, and thus large capital investment. In this paper, we discuss an alternative method of pyrolysis liquid upgrading, using cheap and affordable hydrogen donor additives and catalysts to promote partial deoxygenation at near atmospheric pressure. This approach is preferably to be used as a pre-treatment and stabilizing method for pyrolysis liquids in the close vicinity of remote biomass pyrolysis plants. The pre-treated oil, then can be shipped for further hydrocracking process in a centralized coprocessing facility. Preliminary results from the initial proof of concept experiments involving a $200 \mathrm{~g} / \mathrm{h}$ gas-phase continuous fast catalytic cracking system with continuous coke removal to enhance deoxygenation performance are presented. These results indicate positive impact of catalyst bed on quality and yield of the upgraded bio-oil product in terms of $\mathrm{pH}$, viscosity, degree of deoxygenation, oil yield and concentration of hydrogen in the off gases.
\end{abstract}

\section{Introduction}

Thermochemical conversion of agricultural and forestry residues is considered a potential pathway for generation of renewable heat and power as well as value added chemicals. Unlike petroleum resources, which are found in a highly concentrated form in nature, biomass residues are highly heterogeneous and dispersed along irregular landscapes. The

\footnotetext{
*Corresponding author: Murlidhar.Gupta@Canada.ca
} 
spatial dispersion of raw biomass requires high fractions of parasitic loss per unit of energy during its collection and transportation (haul) to central processing sites such as refineries $[1]$.

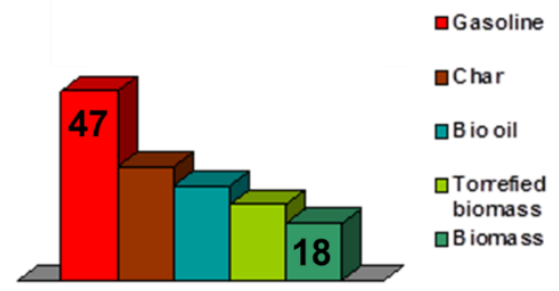

Fig. 1. Relative energy density of bio-oils compared to raw biomass and gasoline.

One of the key pathways to convert the raw biomass into higher density intermediates is fast pyrolysis process. Unlike combustion and gasification processes, pyrolysis is an endothermic thermochemical process and carries some similarity with conventional crude distillation process. In pyrolysis, biomass is heated in absence of any oxidant (air or oxygen) between $400-600^{\circ} \mathrm{C}$ to decompose complex biomass molecules, producing solid (bio-char), pyrolysis liquids and gaseous streams. These liquids are a mixture of highly oxygenated organic compounds. Although polar and nearly immiscible with conventional crude oil fractions, these pyrolysis liquids are widely called bio-oil as they carry the potential to be converted into transportation fuels e.g. gasoline and diesel, etc. [2]. Major issues with biooils are their low $\mathrm{pH}$, increase in viscosity with time (e.g., aging) and close to $50 \%$ oxygen content resulting in low energy density (see Fig. 1).

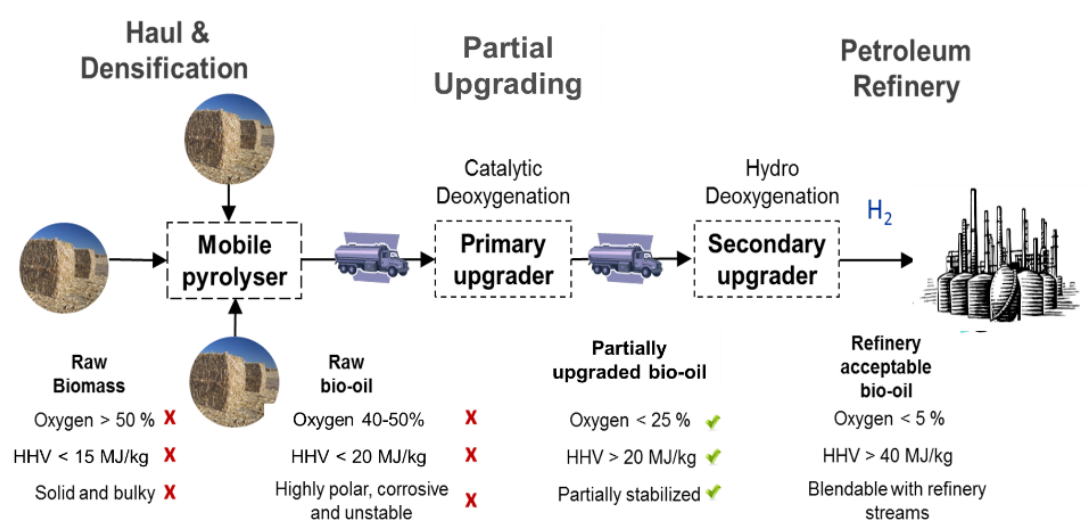

Fig. 2. Sequential upgrading and hauling of bio-oil using partial deoxygenation

\subsection{Bio-oil upgrading}

In order to enhance bio-oil, the $\mathrm{pH}$, stability and energy density, oxygen content of the biooil needs to be addressed. In line with hydrodesulphurization (HDS) process from the petroleum refinery industry, hydrogen pressures greater than 75 bar have been widely suggested for nearly complete hydrodeoxygenation (HDO) of bio-oil [3]. However, producing and handling high pressure hydrogen is technically challenging and expensive at remote sites where most of the agricultural and forestry residues are naturally available. 
Instead of using a highly sophisticated and difficult to maintain HDO facility at a remote sites, an alternate option is primary upgrading through in-situ low pressure partial deoxygenation of raw bio-oil in close vicinity of a biomass pyrolysis facility without using an external hydrogen supply. This way partially reduced levels of oxygen results in higher $\mathrm{pH}$, better stability and greater energy density, making it suitable for long-term storage and transportation to centralized upgrading sites where appropriate resources for secondary upgrading of this partially deoxygenated bio-oil may be available. Fig. 2 shows a conceptual schematic of sequential upgrading and hauling of biomass residues to a petroleum refinery where the deoxygenated bio-oil can be further upgraded with existing refinery infrastructure.

The objective of this study is to develop a simple and partial deoxygenation process using suitable diluents and catalysts, which can be easily integrated at remote sites.

\section{Materials and methods}

Bio-oil sourced from forestry residues were blended with two diluents. The purpose of using these diluents was to prevent coking in the feedline and to explore the possibility of them acting as hydrogen donor. Diluent " $A$ " was a non-polar refinery fraction and was used to make a stable feed blend - for continuous feeding of bio-oil into the reactor system. Diluent "B" was a polar low value industrial by-product. An auger based reactor with a feed capacity

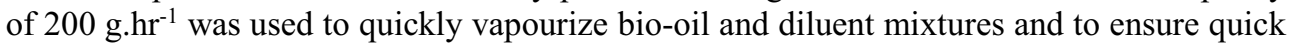
removal of char from vapours proceeding to the fast catalytic cracking reactor (FCCR) (See Fig. 3). The FCCR operated between $400-500^{\circ} \mathrm{C}$ and near-atmospheric pressure, with a packed bed of metal based catalysts. Vapours downstream of reactor were subjected to primary quench at $5^{\circ} \mathrm{C}$ followed by a secondary quench at $-15^{\circ} \mathrm{C}$ to capture condensates for characterization. Off gases were measured and sampled prior to directing them to vent.

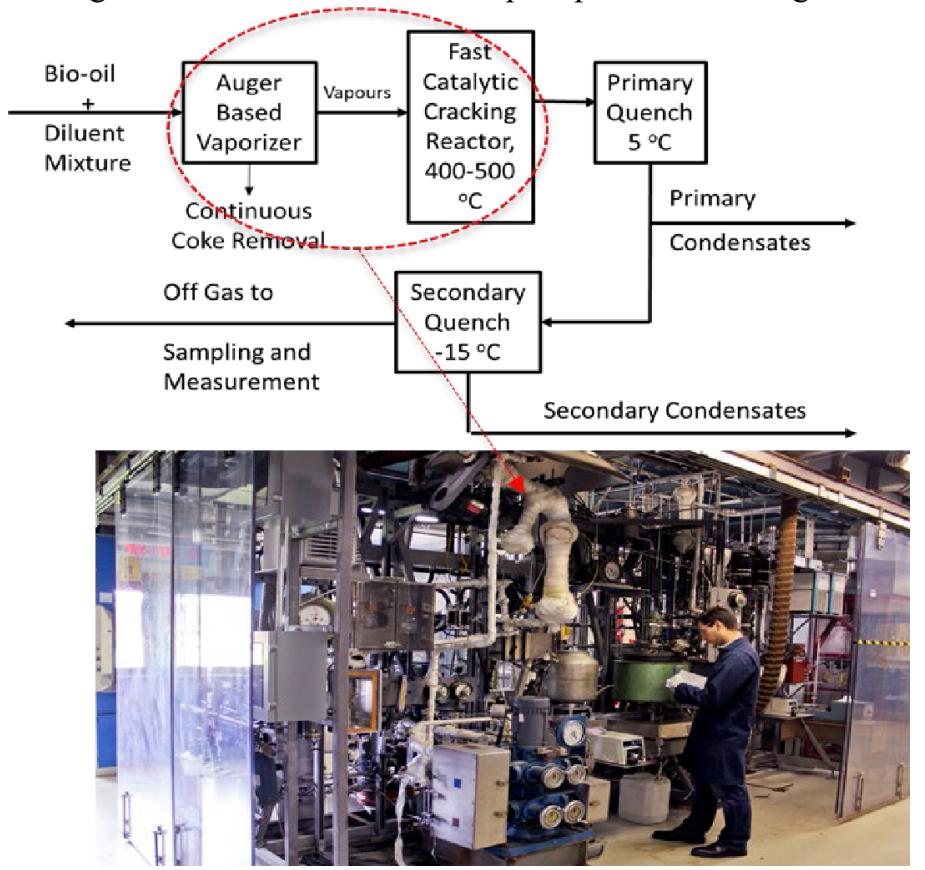

Fig. 3. Fast catalytic cracking reactor 


\section{Results and discussion}

During all experiments, successful mass balances ( $>95 \%)$ were achieved. Fig. 4 shows significant kinematic viscosity decrease from $38 \mathrm{cSt}$ to nearly $3 \mathrm{cST}$ for feed (with diluent A) and upgraded bio-oil (product) respectively. However when metal based catalyst is used this decrease diminishes from $38 \mathrm{cSt}$ for feed (with diluent A) to nearly $5 \mathrm{cSt}$ for product stream. This shows that use of metal catalyst under the given conditions did not make a difference.

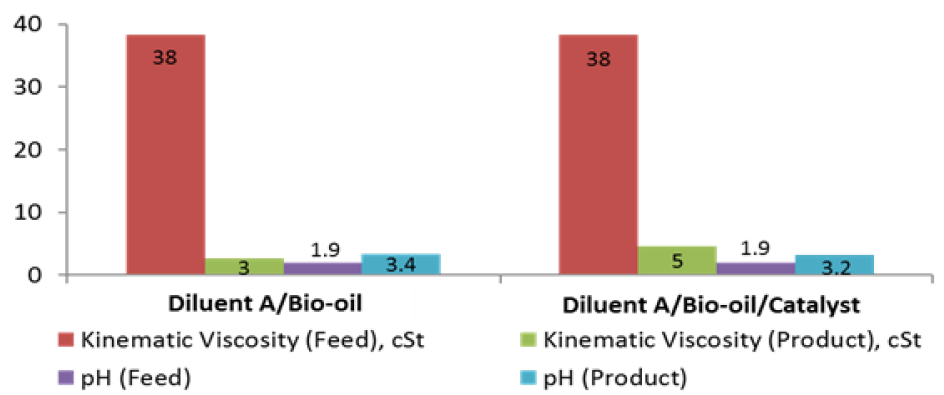

Fig. 4. Comparative performance of bio-oil feed with and without metal based catalyst.

$\mathrm{pH}$ measurement was used to determine the acidic characteristic of bio-oil and of the product. Fig. 4 shows the acidity of the product decreases with $\mathrm{pH}$ increases in the product when compared to feed. This is a desirable outcome. However, the effect of catalyst on $\mathrm{pH}$ is not clear, as with or without catalyst the increase in $\mathrm{pH}$ is around $68 \%$.

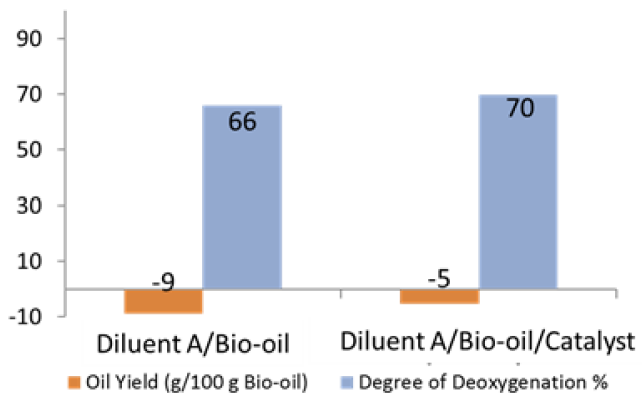

Fig. 5. Oil yield and degree of deoxygenation

A positive oil yield shows that the process has not consumed the diluent, rather the biooil is being consumed to form the product. This is a desired outcome e.g. diluent fraction can be recycled into the process whereas a negative yield would have indicated that diluent had been consumed in the process and the process would require additional make up for diluent. In case of Diluent A/Bio-oil feed with and without catalyst, we noticed a negative yield ranging from -5 to $-9 \mathrm{~g}$ per $100 \mathrm{~g}$ bio-oil, indicating that process with this outcome is not acceptable (See Fig. 5).

The mean value of degree of deoxygenation is more than $50 \%$ for the cases with and without catalyst (see Fig. 6). However, the degree of deoxygenation should always be analysed in conjunction with the oil yield. For a meaningful upgrading of bio-oil, both values should be positive and the yield needs to be enhanced through proper process optimization of parameters and requires further investigation.

Fig. 6 shows the hydrogen concentration in the off gases. In both cases e.g. with Diluent A and with Diluent B, use of catalyst shows significant increase in hydrogen concentration in the off gases- from 8 to $21 \%$ for diluent $\mathrm{A}$ and to $17 \%$ for diluent $\mathrm{B}$. This is an interesting 
outcome although not desired for producing liquid fuels but highly desirable for producing hydrogen rich gases for fuels and feedstock.

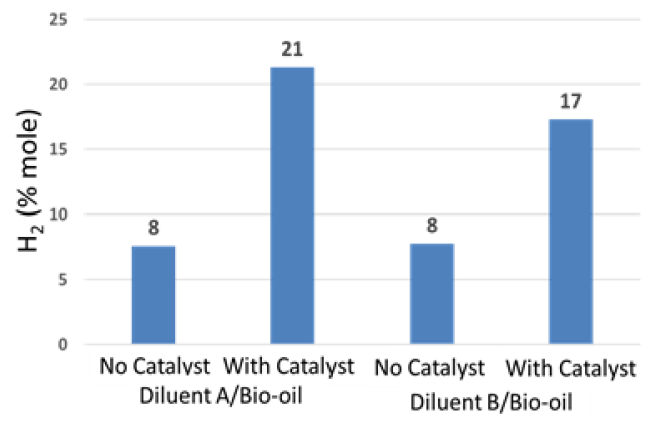

Fig. 6. Concentration of hydrogen in the off gases.

\section{Preliminary conclusions}

- Significant reduction in kinematic viscosity was observed.

- $\quad \mathrm{pH}$ of product nearly doubled, indicating lower corrosiveness.

- Degree of deoxygenation achieved was greater than $50 \%$, however negative values of yield were also observed.

- Significant increase in the hydrogen concentration was observed in the off gases using catalytic cracking.

- Future efforts should be focussed on optimizing the process with better configuration of reactor temperature, diluents and catalysts.

The financial support from Natural Resources Canada, the Program of Energy Research and Development, is acknowledged. Technical help from Tim Shaw is greatly appreciated.

\section{References}

1. M. Vaezi, A.K. Katta and A. Kumar, Biosystems Engineering 118, 52-67 (2014)

2. D. Mohan, C.U. Pittman and P.H. Steele, Energy \& Fuels, 20, 848-889 (2006)

3. P.M. Mortensen, J.-D. Grunwaldt, P.A. Jensen, K.G. Knudsen and A.D. Jensen, Applied Catalysis A: General, 407, 1-19 (2011) 